\title{
EDITORIAL
}

\section{Strengthening families: a key recommendation of the Joint Learning Initiative on Children and AIDS (JLICA)}

In late 2006, a global effort to mobilise support for children affected by HIV and AIDS was launched in London with the support of a group of leading activists, scholars and funders. The Joint Learning Initiative on Children and AIDS (JLICA) aimed to collate and critically analyse available knowledge and experience about the impact of HIV and AIDS on children, and to make a set of high-level recommendations around which the global community could marshall resources, commitment and action.

The JLICA built on the methods of the Joint Learning Initiative on Human Resources for Health, also led by Lincoln Chen, now President of the China Medical Board in New York (Joint Learning Initiative, 2004). Peter Bell, former President of CARE, now with the Hauser Center for Nonprofit Organizations at Harvard University, and Agnes Binagwaho, former Executive Secretary of Rwanda's National AIDS Control Commission, now the Permanent Secretary of the Ministry of Health of Rwanda, were invited to be the overall co-chairs of the JLICA.

During planning meetings prior to its launch, it was agreed that the JLICA would be structured to build on the enormous learning summarised in the widely endorsed Framework for the Protection, Care and Support of Orphans and Vulnerable Children Living in a World with HIV and AIDS (UNICEF, 2004). The key strategies proposed by the Framework are to: strengthen the capacity of families to protect and care for orphans and vulnerable children by prolonging the lives of parents and providing economic, psychosocial and other support; mobilise and support community-based responses; ensure access for orphans and vulnerable children to essential services, including education, health care, birth registration and others; ensure that governments protect the most vulnerable children through improved policy and legislation and by channelling resources to families and communities, and raise awareness at all levels through advocacy and social mobilisation to create a supportive environment for children and families.

Four Learning Groups (LGs) were formed in the JLICA to mirror the proposed strategies, while advocacy and social mobilisation were adopted as goals of the JLICA as a whole:
- LG 1: Strengthening Families, co-chaired by Linda Richter and Lorraine Sherr (earlier Angela Wakhweya).

- LG 2: Community Action, co-chaired by Geoff Foster and Madhu Deshmuck.

- LG 3: Services and Human Rights, co-chaired by Jim Yong Kim and Lydia Mungherera.

- LG 4: Social and Economic Policies, cochaired by Alex de Waal and Masuma Mamdani.

LG 1: Strengthening Families formed an advisory group to guide the formulation of key questions and issues to be addressed over the course of the next two years. A call for papers was widely advertised and 13 papers were commissioned to address the following 10 questions: on which children and families should we focus? What evidence is available on which children are vulnerable, what can be done to assist vulnerable children, and how good is the research? What aspects of the HIV/AIDS epidemic impact on children, how and why? How are families changing as a result of adult illness and death associated with HIV and AIDS? In what way are children's health, education and development affected by the HIV/ AIDS epidemic? What does knowledge and experience of other crises teach us about the AIDS response for children and families? What can we learn from carefully evaluated family strengthening efforts in fields other than HIV and AIDS that can be usefully applied in hard-hit countries in eastern and southern Africa? What programmatic experience has been gained in strengthening families in the HIV/AIDS field? What promising directions are there for the future and what do they suggest? What mistakes have been made, how can they be avoided in the future, and what now needs to be done?

We tried, but failed to commission a paper on abuse, neglect and community-based child protection strategies for low-income countries.

By and large, the papers in LG 1 are based on comprehensive systematic reviews of available published material. Where needed, unpublished grey literature was also consulted. LG 1 authors met three times in the course of two years, and communicated electronically between times to ensure that their work 
was complementary. The JLICA met five times during this period to enable an understanding of the problem and key recommendations to be drawn from the diversity of work done across the four LGs.

The main conclusions of the JLICA draw heavily on the work done in LG 1: Strengthening Families, and the ideas generated in LG 1 greatly influenced the analyses of LGs 2, 3 and 4 .

According to the JLICA, what is needed at a global, regional, national and local level is to:

1. Harness national social protection for vulnerable families as a critical lever to improve children's outcomes in the context of HIV and AIDS.

2. Target benefits to families and children based on need, not on HIV or orphan status.

3. Reinforce families' long-term caring capacities as the basis of a sustainable response to children affected by HIV and AIDS.

4. Strengthen community action in support of children affected by AIDS and ensure that community voices inform decision making on all policies and programmes.

5. Implement family centred services integrating health, education and social support.

6. Redirect HIV prevention to redress the social and economic inequalities that increase girls' and women's vulnerability.

7. Strengthen the evidence base of policies and programmes that work for children.

This special issue on Strengthening Families reflects some of the work of LG 1: Strengthening Families. The original papers, and the integrated final report, are long and very detailed. They can be accessed in full on the web pages of the JLICA (http://www.jlica. org) and the Human Sciences Research Council (http://www.hsrc.ac.za/JLICA-81.phtml).

The first paper, Strengthening Families to Support Children Affected by HIV and AIDS, provides the rationale for the work of LG 1, summarises the key arguments made by authors across LG 1, and closes with the main recommendations for supporting families and children. The following papers in the special issue deal with one or other detailed aspect of the reviews conducted for the JLICA.

\section{References}

Joint Learning Initiative. (2004). Human resources for health: Overcoming the crisis. Cambridge, MA: Harvard University Press.

UNICEF. (2004). Framework for the protection, care and support of orphans and vulnerable children living in a world with HIV and AIDS. New York: United Nations Children's Fund.

Linda M. Richter

Human Sciences Research Council and University

of KwaZulu-Natal

South Africa

Email: LRichter@hsrc.ac.za

Lorraine Sherr

Department of Infection and Population Health Royal Free and University College Medical School

University College, London

Email: 1.sherr@pcps.ucl.ac.uk 